varieties of behaviour which have been recorded; but it is doubtful whether there is any entomologist better qualified to write on this subject than Prof. Richards. This book will certainly be welcomed by all who are interested in the subject as it brings together in a most readable form the results of many of the more recent investigations on the biology of onts, bees, wesps and termites by workers in various countries.

After dealing briefly with such matters as instinctive behaviour, learning and orientation, the author goes on to discuss, in the first chapter, the probable way in which insect social behaviour evolved from the solitary behaviour exhibited by most insects, through various sub-social stages such as those shown by the common earwig, some dung beetles, bees and wasps, to the elaborate social behaviour of ants, honeybees, termites and some wasps.

In subsequent chapters many aspects of the behaviour of solitary and social wasps, of solitary and social bees, including humble bees and stingless bees as well as honeybees, and of both ants and termites are described. In a most valuable chapter dealing with social parasites the author expounds theories of the origin of the cuckoo bees and wasps which to-day do not possess any worker castes, and also discusses the development of cuckoo habits in ants, which exhibit all sorts of stages in the development of such behaviour, ending up in workerless, degenerate parasites.

When writing of the termites Prof. Richards stresses the fact that, although they show certain remarkable analogies with other social insects, in reality the differences between the termites and all other social insects are profound and more important than the resemblances. He traces the peculiarities of the termites to two basic facts about their societies. First, that males and females are represented at all stages and in all castes, this being associated with a different method of sex-determination ; and, second, that development is gradual, over a series of moults, with no helpless grub-stage. Thus their whole caste system is much more flexible and complicated.

In a most stimulating final chapter the author discusses some of the problems which social animals have had to overcome during the course of their evolution.

This is certainly a book which can be recommended unreservedly to all students of animal behaviour, one's only regret being that it is not longer.

C. G. Butler

\section{SOCIAL LIFE AND PHILOSOPHY OF ABORIGINES}

The World of Primitive Man

By Paul Radin. (Life of Science Library No. 26.) Pp. xi +370 . (New York: Henry Schuman, Ine., 1953.) 5 dollars.

ATHOUGH this book contains many original, $A$ and often profound, observations on the mind and customs of primitive man, it suffers from the lack of an exact definition of the material studied. The author attempts, we are told, "to portray the civilizations of primitive peoples and the world in which they lived". The use of the past tense here is confusing; for most of the examples given are of present-day tribes and the world in which they are living to-day, contaminated as they have been by Western civilization. The words "primitive" and "aboriginal" are used interchangeably (as well as "civilization" and "culture", a synonym with which many would quarrel). The dictionary defines aboriginal as "indigenous, existing in a land at the dawn of history, or before the arrival of colonists", and the author accepts most African tribes as aboriginal only with "many provisos" for this very reason, because they have been transformed by colonists and invaders. Since most of the material is drawn from contemporary sources (largely the New World), this proviso should, strictly speaking, apply to nearly all of it. If it is an attempt to portray the world in which they lived in the past, this is: another matter ; but in this case, most of the material would be irrelevant.

There is throughout a rather subjective bias. towards the "positive achievernents" that "aboriginal philosophers and theorists have made to the history of thought" ; the "negative" side (by which is implied magic, and the role of fear) is not stressed. These practices and emotions, the author concludes (contrary to most social anthropologists), "interfere little with the orderly processes of life and do not hinder rational and objective thinking". Taboos, for example, are often winked at, or got round, and examples are given to prove the point. But again, the examples are of present-day tribes, who have had contact with Western civilizations: it is the world in which they are living rather than have lived.

Aboriginal philosophy is summarized as "do what you like, but face the consequences", for every individual has the right not only to the irreducible economic minimum, but also to self-expression and the freedom of movement. The "consequences" may be social ostracism, but imprisonment is an uncommon form of punishment. A murderer is seldom sentenced to death, for death meant an economic weakening of the community and, as such, demanded not simply revenge but also replacement for loss with damages. Law, authority and property are never static, but circulate. The authority of an individual (the author contends) is largely fictitious or symbolic; there is seldom despotism, for power resides in the group. Status is never inherited, it is conferred at puberty, and therefore infanticide is not a crime; on the death of an individual, status or authority reverts to the group and has to be conferred again on another individual by the group. Customs only become law in emergencies, and are not obeyed because of a rigid tradition but only from the conviction that they have worked in the case of the elders. Personal property is reduced to a minimum, and anything above this is kept in compulsory movement; its value becomes enhanced as it passes from one person to the next and, although the owner sees no profit, he gains in prestige by these transactions.

One is left with a rosy picture of the happy savage enjoying "an amazing degree of social and political integration" and "the concept of personal security which transcends all governmental forms and all tribal and group interests and conflicts". In spite of the uncomfortable feeling that this picture is particular rather than general, however, one is also left stimulated, and with a better understanding of the minds of men with different cultures from our own.

Sonia Cole 